\title{
Garcinia indica Choisy: Screening of Location for Donor Female Mother Plants for Micropropagation with Effective Protocol for Establishment of Sterile and Healthy Cultures
}

\author{
Shubha S Manvi and Varsha A Parasharami* \\ PTC-Biochemical Division, CSIR-National Chemical Laboratory, India \\ *Corresponding Author: Varsha A Parasharami, Senior Scientist, PTC-Biochemical Sciences, CSIR-National Chemical Laboratory, Pune, \\ Maharashtra, India.
}

Received: May 16,2019; Published: June 06, 2019

DOI: 10.31080/ASAG.2019.03.0514

\begin{abstract}
The current study aims to micropropagate female cultures of Garcinia indica Choisy ('Kokum') and hence, focuses on improvising sterilization techniques for ensuring high survival of the explants of $G$. indica; an endemic tree species of the Western Ghats. Kokum shoot buds were collected from fruiting mother trees across nine different locations in Konkan, Maharashtra, India. G. indica is a proliferent producer of phenols and polyphenols and is also prone to certain endogenous contamination. Treatment of the explants with sterile distilled water, Tweens $20,10 \%(\mathrm{v} / \mathrm{v})$ savlon and $0.1 \%$ PVP along with $1 \%$ anti-fungal agent bavistin followed by an aseptic treatment with $0.75 \% \mathrm{HgCl}_{2}$ and drying of shoots for 60 minutes before inoculations resulted in $87 \%$ survival of healthy, sterile buds. Of the nine locations, donor plants growing naturally from the villages of Sarole, plantations in Panose-Koste, and the grafted varieties of Hatis and Amruta from Balasaheb Deshmukh Krishi Vidyapeeth, Dapoli gave an average sprouting of 24.66\%. The present study is the first of its kind to publish a detailed location-wise collection of $G$. indica mother shoots and standardize a sterilization protocol for clonal propagation of $G$. indica female plants.
\end{abstract}

Keywords: G. indica; Kokum; Phenols; Browning; Contamination; Sterilization; Micropropagation

\section{Abbreviations}

IBA: Indole-6-Butyric Acid; PVP: Polyvinyl Pyropropiolate; SDW: Sterile Distilled Water; $\mathrm{WM}_{\mathrm{I}}$ : Woody Plant Initiation Media; $\mathrm{WM}_{\mathrm{M}}$ Woody Plant Multiplication Media; LAF: Laminar Air Flow.

\section{Introduction}

Haberlandt's theory of Totipotency allowed tremendous advances in Plant Sciences as in vitro propagation of selected, desired plants became a reality and an essential part of plant sciences [1]. However, even with innumerable advantages, growing the plant outside their niche requires optimization of various parameters of growth along with overcoming the innumerable endogenous and exogenous microbial contamination the donor plant harbors [2-4]. The present study discusses sterilization of one such plant species called 'Garcinia indica', family Clusiaceae; a recalcitrant, woody plant which is an important endemic species in the Western Ghats, subsequently leading to its large scale in vitro propagation. Commonly known as 'Kokum', it is a valuable medicinal Angiosperm exclusive to the forests of Konkan in Maharashtra to Mysore region of Karnataka; but is enlisted as endangered species of Southern states in India [5-8]. The tree bears purple, globular fruits seasonally, from March to June [5]. These fruits are infamous of its pharmaceutical properties due to the presence of Anthocyanins, Hydroxycitric acid, Garcinol and many other important phenolics such as tannins and Flavanoids [6]. Since ancient times, the fruit is seeked for its digestive, immune building and anti-obesetic activities [5]. 
Seed or vegetative propagation is the conventional way to propagate kokum [5]. Cloning by vegetative propagation of carefully selected explants can result in reproduction of stable genotypes, as true-to-type cloning of selected elite trees omits the possibility of weak genotypes and ensures propagation of fruit bearing female trees alone $[9,10]$. Apart from recalcitrance of $G$. indica plants, the two most major but basic hurdles which discourage clonal propagation are microbial contamination and exudation of phenolic compounds during initial stages of tissue culture [11-13]. The present study aims to establish an efficient technique to reduce microbial contamination and ensure survival of maximum sterile cultures of $G$. indica, for large scale clonal propagation of this species. The technique is such that while eliminating microbial contamination, the procedure also ensures sprouting Garcinia indica is an underexploited medicinal tree for research and its importance in the pharmaceutical and cottage industries has been undervalued $[7,10]$.

\section{Materials and Methods}

\section{Location of the female donor Plant}

The mother plant shoots used for the study were collected from nine different locations in and around Konkan region of Maharashtra, where Kokum is a natively growing tree. The journey started from Sarole village near Tamhini Ghats up to Dapoli in Ratnagiri. Figure 1 and Table 1 shows different collection sites with their respective longitudes and latitudes along with the Mean Sea Levels MSL (calculated using Oregon 550, Garmin, USA) of each location, collected during of three years- 2017, 2018 and 2019.

\begin{tabular}{|c|c|c|c|c|c|}
\hline Sr. No. & Location & $\begin{array}{c}\text { Natural/plantation } \\
\text { Elite and other details }\end{array}$ & $\begin{array}{c}\text { Distance from } \\
\text { CSIR-NCL, Pune (km) }\end{array}$ & Latitude/Longitude & MSL \\
\hline 1. & Sarole & $\begin{array}{c}\text { Natural } \\
\text { Normal fruits }\end{array}$ & 65.9 & $\begin{array}{l}18^{\circ} 28^{\prime} 34^{\prime \prime} \mathrm{N} \\
73^{\circ} 26^{\prime} 35^{\prime \prime} \mathrm{E}\end{array}$ & $623 m$ \\
\hline 2. & Nivegaon & $\begin{array}{c}\text { Plantation } \\
\text { Normal fruits }\end{array}$ & 67.6 & $\begin{array}{l}18^{\circ} 29^{\prime} 36^{\prime \prime} \mathrm{N} \\
73^{\circ} 25^{\prime} 34^{\prime \prime} \mathrm{E}\end{array}$ & $619 \mathrm{~m}$ \\
\hline 3. & Kumbhalavane & $\begin{array}{c}\text { Natural } \\
\text { Normal fruits }\end{array}$ & 174 & $\begin{array}{l}17.9435^{\circ} \mathrm{N} \\
73.5353^{\circ} \mathrm{E}\end{array}$ & $779 \mathrm{~m}$ \\
\hline 4. & Pratapgad & $\begin{array}{c}\text { Natural } \\
\text { Normal fruits }\end{array}$ & 171 & $\begin{array}{l}17.9335^{\circ} \mathrm{N} \\
73.5806^{\circ} \mathrm{E}\end{array}$ & $760 \mathrm{~m}$ \\
\hline 5. & Koste & $\begin{array}{l}\text { Plantation } \\
\text { Elite fruit }\end{array}$ & 102 & $\begin{array}{l}18^{\circ} 17^{\prime} 21.09^{\prime \prime} \mathrm{N} \\
73^{\circ} 18^{\prime} 29.17^{\prime \prime} \mathrm{E}\end{array}$ & $52 \mathrm{~m}$ \\
\hline 6. & Panose & $\begin{array}{l}\text { Plantation } \\
\text { Elite fruit }\end{array}$ & 104 & $\begin{array}{l}18^{\circ} 15^{\prime} 33.34^{\prime \prime} \mathrm{N} \\
73^{\circ} 17^{\prime} 21.09^{\prime \prime} \mathrm{E}\end{array}$ & $28 \mathrm{~m}$ \\
\hline 7. & Amruta- Dapoli & $\begin{array}{c}\text { Grafted Plantation } \\
\text { Of Amruta normal } \\
\text { released Varity }\end{array}$ & 193 & $\begin{array}{l}17^{\circ} 45^{\prime} 06.75^{\prime \prime} \mathrm{N} \\
73^{\circ} 10^{\prime} 35.42^{\prime \prime} \mathrm{E}\end{array}$ & $181 \mathrm{~m}$ \\
\hline 8. & $\begin{array}{c}\text { Shirgaon } \\
\text { (Amruta mother plant) }\end{array}$ & $\begin{array}{c}\text { Natural } \\
\text { Normal fruits }\end{array}$ & 225 & $\begin{array}{l}\mathrm{E} 17.453^{\circ} \mathrm{N} \\
73.6232^{\circ} \mathrm{E}\end{array}$ & $35 \mathrm{~m}$ \\
\hline 9. & $\begin{array}{c}\text { Hatis- Ratnagiri } \\
\text { Bhatye Research center }\end{array}$ & Hatis Early Varity & 310 & $\begin{array}{l}16^{\circ} 58^{\prime} 33.64^{\prime \prime} \mathrm{N} \\
73^{\circ} 10^{\prime} 35.42^{\prime \prime} \mathrm{E}\end{array}$ & $13 \mathrm{~m}$ \\
\hline
\end{tabular}

Table 1: The collection sites of Kokum donor plants with the co-ordinates and Mean Sea Levels depicting the varying difference in altitudes Kokum growing regions. The collection was done between January to June each year from 2017 to 2019. 




Figure 1: Location sites of Garcinia indica across the Konkan region, collected through the years 2017-2019.

Figure 1a: Western Ghats stretch specified on the Outline Map of India.

Figure 1b: Kokum growing Regions in Western Ghats

Figure 1c: The route showing G. indica collection sites from CSIR-NCL, Pune.

Source- Google Maps

\section{Preservation of the collected shoot bud material}

During the 10 to 15 hours of transport, collected materials were wrapped in filter papers inside zip-lock pouches. On reaching the laboratory, they were cut into $8-10 \mathrm{~cm}$ long twigs and washed thoroughly with Sterile Distilled Water. They were segregated according to their apical or axillary origin and cut into shoots of 2 to $6 \mathrm{~cm}$, each with leaf primordia [4], now termed as explants. These explants were further categorized into 'soft buds' and 'hard buds' with respect to their thickness and stored in sterile Jam bottles of dimensions $105 \mathrm{~cm}$ X $55 \mathrm{~cm}$.

\section{Sterilization treatment}

The cut shoots were experimented with three different sterilization techniques to standardize the procedure and achieve maximum number of healthy, contamination free sprouted buds. The experiments were done in sets of three where 45 explants collected from Sarole village were given three types of treatmentsin the first protocol, the buds were soaked in running tap water for sixty minutes and rinsed with labolene (Qualigens, India) and later washed with $10 \%(\mathrm{v} / \mathrm{v})$ Savlon (Johnson \&Johnson) followed by soaking in $0.1 \%$ PVP (Sigma, USA) for 30minute and then an antifungal treatment with $1 \%(\mathrm{w} / \mathrm{v})$ Bavistin (BAIF, India) . These disinfected buds were taken into the LAF for further treatment where the buds were rinsed with $70 \%$ ethanol $(\mathrm{v} / \mathrm{v})$ and treated trice with $1 \% \mathrm{HgCl}_{2}$ (Qualigens, India) for 7 minutes [8]. In the second method, the procedure was kept the same with slight improvisations. Here, SDW was used for the initial wash instead of running tap water [4], Labolene was replaced with Tweens20 (HiMedia Laboratories, India) and $\mathrm{NaOCl}$ (HiMedia Laboratories, India) $[4,14]$ was used instead of $\mathrm{HgCl}_{2}$. Treatment with $70 \%$ ethanol was eliminated. The treated shoot buds were thoroughly dried in the LAF for 60 minutes before inoculating them in the $\mathrm{WM}_{\mathrm{I}}$ media, whose media composition is mentioned in Deodhar, et al. [8] with 400mg/L Taxim (AlChem, India) [10]. The other protocols were maintained as mentioned in the first procedure. In the third protocol however, $\mathrm{NaOCl}$ was replaced with a lower concentration, i.e. $0.75 \% \mathrm{HgCl}_{2}$ [3]. The rest of the procedure was similar to the second protocol. In the second and the third protocols, hard buds were socked for 12 minutes in $\mathrm{HgCl}_{2} / \mathrm{NaOCl}$ solution whereas softer buds were socked for 5-7 minutes for sterilization depending upon their softness. The buds were washed thoroughly with sterile distilled water (SDW) in between each wash to remove any remnant traces of $\mathrm{HgCl}_{2}$ or $\mathrm{NaOCl}$. The procedure which gave maximum number of sterile, healthy sprouted buds was used as a standard protocol for future sterilization treatments throughout the study

Post-Sterilization treatment and initiation of multiplication stage

The test-tubes inoculated with the explants were tied in bundles of seven and incubated at $27^{\circ} \mathrm{C}$ with a $16 / 24 \mathrm{hr}$ light period with 1500lux illumination in the culture room [10]. Within 48 hours of inoculation, the first contaminants start to show [4]. Phenolic exudation soon follows within the first 48 to 60 hours and if left unattended, fungal and bacterial colonies begin to grow on these exudates, resulting in death of the explants [3].

The 'bud break' occurs in 10 to 18 days of inoculation in the $\mathrm{WM}_{\mathrm{I}}$ medium and grows on axis petioles and shoots [15]. The fragile petioles that were about to break from the shoot buds were removed immediately in aseptic environment using sterile instruments. The cultures were shifted into a fresh $\mathrm{WM}_{\mathrm{I}}$ media after every 35-45 days till the buds began sprouting, after which 
the buds were inoculated in autoclavable jam bottles containing $\mathrm{WM}_{1}$ media. This stage marks the completion of the $\mathrm{I}_{3}$ phase and beginning of the $\mathrm{S}_{0}$ phase with the multiplication media. After 30-60 days of growth in the culture bottles, the sprouted buds are shifted to a fresh medium in $250 \mathrm{~mL}$ conical flasks for shoot Multiplication in $\mathrm{WM}_{\mathrm{M}}$ composed of WPM, Kin $1 \mathrm{mg} / \mathrm{L}$ and BAP $2 \mathrm{mg} / \mathrm{L}$ and IBA $1 \mathrm{mg} / \mathrm{L}$ and $200 \mathrm{mg} / \mathrm{L}$ Taxim along with other $\mathrm{WM}_{\mathrm{I}}$ media components and are regularly subcultured after 50-60 days $[8,10]$ until the $\mathrm{S}_{4}$ stage [10], after which these shoots are subjected to in vitro and ex vitro rooting trials, details of which have been published in Mulik., et al, 2019 [10].

\section{Results and Discussion}

In micropropagation, quality of the donor mother plant plays a critical role in determining the success of a tissue culture operation $[1,4,9]$. One of the aims of the above mentioned study was to evaluate the donor mother tree at its natural location for the selection of the shoot bud material. The locations were carefully chosen keeping in mind the varying range of Mean Sea Level's (MSL) from highest in Pratapgad-Kumbhalavane (779M) to lowest in Dapoli (13M). The twigs were collected from each location in the months of January to May in the years 2017-19, for culture establishment and studies. More than 6000 collected from all these locations explants were inoculated in the span of three years.

\section{Location of elite mother plant collection}

The cultures were collected from the Konkan belt in Western Ghats covering a vast area of 60 to $330 \mathrm{~km}$ from CSIR-National Chemical Laboratory in Pune. Figure 1. Traces the locations covered and Table 1 gives a detailed description of the geographical co-ordinates of these locations.
The nearest location at $65.9 \mathrm{~km}$ from Pune was a village named Sarole near Tamhini Ghats where Kokum trees of more than 60-70 years were found growing naturally. Healthy twigs were collected and stored as mentioned in material and methods. On 10-30km from Sarole, other villages like Nivegaon, Dongarwadi, and Adharwadi were also explored for their naturally growing kokum trees. On travelling a few kilometers ahead, donor mother plant twigs were collected from the private plantations of Kokum in the villages of Panose and Koste. In both these plantations, 1-2 trees bearing bigger sized and deep purple colored fruits were identified as "elite fruit trees". Figure 2.a and 2.b. shows natural and plantation trees of Sarole and Panose respectively. Figure 3.a. shows fruits of trees collected from Koste tree of Elite variety whereas Figure 3.b draws comparison between fruits from Panose Elite tree and a normal Panose tree. Figure 3.c. shows Kokum fruits collected from the recently released grafted variety of Kokum named 'Amruta'. The two varieties of kokum "Amruta" and "Hatis" released from "Balasaheb Deshmukh Krishi Vidyapeeth" Dapoli, were selected for clonal propagation. Mother cultures from two Hatis-mother trees at Coconut Research Center Bhatye, at Ratnagiri and one Amruta Mother Tree in Shirgaon village near Ratnagiri were collected for micropropagation as well. The material collected from this site is said to be of early fruiting variety which produces healthy, ripe fruits by the month of March, as opposed to May-June, which is the natural fruiting period for $G$. indica. Healthy looking donor branches were collected with the aim of clonal propagation of healthy explants and were named according to their location of collection while maintaining the cultures in the laboratory.
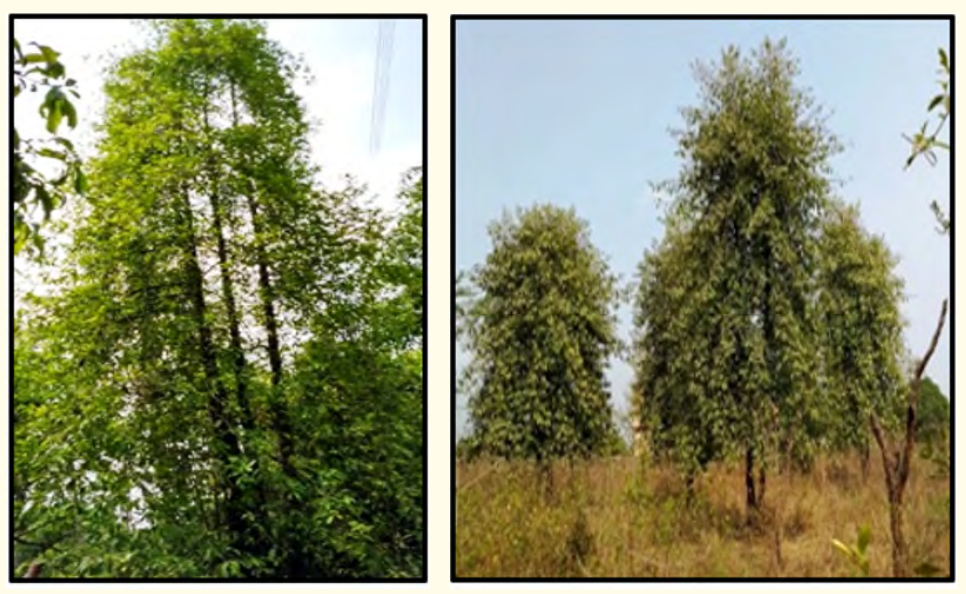

Figure 2.a: Sarole Naturally growing trees.

Figure 2.b: Panose Plantation trees of G. indica 

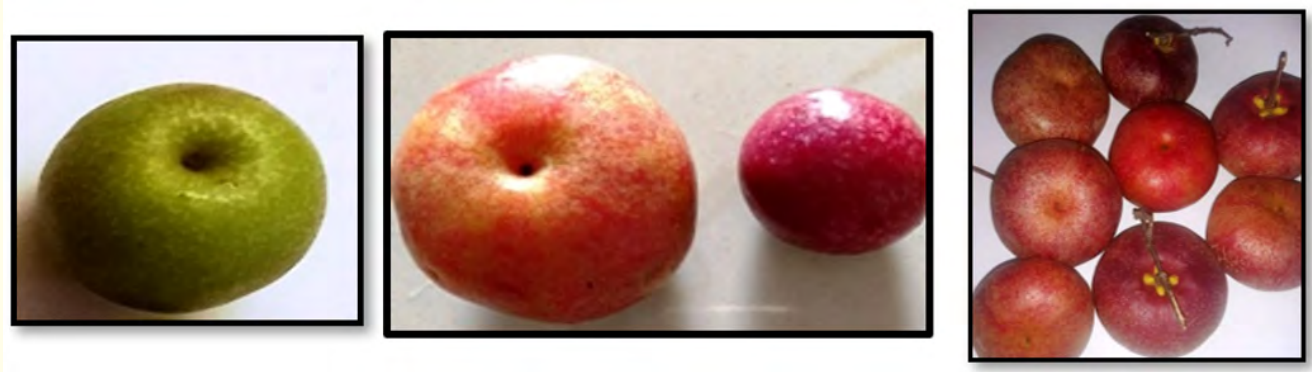

Figure 3.a: Elite fruit of $G$. indica from Koste plantation tree.

Figure 3.b: Mature 'elite' and normal fruit from Panose plantation.

Figure 3.c: Fruits from 'Amruta' grafted variety tree from Dapoli.

Preservation of the Collected Shoot Bud Material for in vitro propagation

During the extensive ten to fifteen hours of transport, the collected donor mother plant materials were wrapped in filter papers and stored in zip-lock pouches to reduce the rate of transpiration and retain the moisture before processing. On reaching the laboratory, the materials were cut into 8 to $12 \mathrm{~cm}$ long twigs and were washed thoroughly in SDW to wash away any adhered dirt and external contamination. Previously, washing with running tap water has been reported by a few authors $[4,8]$. The buds were cut seperately with respect to its apical and axillary origin where the meristematic tissues are present $[2,16]$. This incision is a crucial step as damaging the tissues containing plastids which suspend polyphenols for metabolism of phenols can get damaged which ends up browning the growth media [3]. The explants were cut into lengths of $3 \mathrm{~cm}$ to $5 \mathrm{~cm}$, each containing a leaf primordia bud along with petiole. Each of the nine location explants were segregated depending upon their apical/axillary; softness/hardness and stored seperately in jam bottles. Segregating the buds according their origin and thickness ensured that the sterilization treatment is given accordingly. These cut explants were immediately subjected to sterilization treatment to reduce contamination and browning.

\section{Sterilization procedure}

The disinfection steps were standardized in the laboratory and published in 2014 [8]. However, a few modifications were done to suit the hardness or the softness of the explants. Loses of in vitro grown cultures due to contamination is a major concern $[13,17]$. To minimize these, the protocol was standardized. From all the three procedures carried out, Procedure with Tweens20 as the surfactant and $0.75 \% \mathrm{HgCl}_{2}$ minimized the losses in culture shoots due to microbial contamination. Composed mainly of lauric acid, Tweens 20 plays a better role of surfactant as compared to Labolene which is a sodium hydrate detergent [14]. PVP helps in removing phenolic compounds by forming hydrogen bonds with them [18]. By our observation, drying of the explants for 60minutes before inoculation in the test tube plays a major role in completely eliminating phenolic exudation and thus prevents browning of the medium. With this procedure, $87 \%$ culture explants were healthy and sterile. $\mathrm{HgCl}_{2}$ is a potent toxic to microbial contamination and ensures killing of most of the thriving bacteria. Although a few papers have reported discouragement towards the usage mercuric chloride and rather quoted sodium hypochlorite as a more suitable option, we made two important observations- the medium starts browning within 48 hours when $\mathrm{NaOCl}$ is used and as most of the mercuric chloride is washed away during the rinsing process, it can be used as a sterilant as most of it was washed away during the rinsing process [2,3]. Addition of appropriate amounts of taxim and bavistin in the media has proven to prevent endogenous microbial contamination to a great extent, as discussed in Parasharami., et al. 2002 in case of Pinus roxburghii [19]. It was observed that every step of disinfection and sterilization were critical as skipping even one resulted in contamination and low sterilization rates. Figure a shows the success percentage of the three procedures followed for the shoot buds collected from Sarole village near Tamhini Ghats. 


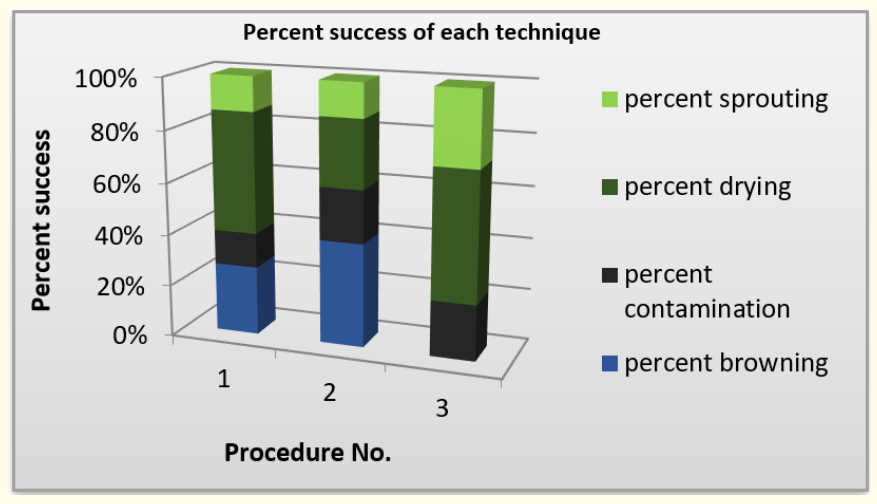

Figure a: Percent success of each of the procedure followed for sterilization treatment of the explants.

It is evident that procedure No.3 gave the highest number of sprouting with zero browning of the media.

Table 2 Shows the results obtained after sprouting of these sterilized explants after 40-45 days of incubations in the culture room. More than 6000 buds were collected from different locations and an average of $24 \%$ sterile sprouted cultures were obtained, where cultures collected from the trees over 60-70 years of age from Sarole village gave a sprouting of $10.8 \%$, the minimum, whereas the maximum sprouting of 53\% was achieved from the grafted variety of Hatis. To our knowledge, this is a first of its kind study conducted successfully using $G$. indica mature female plant explants for meristem cultures.

\begin{tabular}{|c|c|c|c|c|c|c|}
\hline Sr. no. & Location & $\begin{array}{c}\text { Total no. of buds } \\
\text { inoculated from } \\
\mathbf{2 0 1 7 - 1 8 - 1 9}\end{array}$ & $\begin{array}{c}\text { No. of Sterile } \\
\text { Buds after } \\
\mathbf{4 5} \text { days- I }\end{array}$ & $\begin{array}{c}\text { Percent } \\
\text { sterility }\end{array}$ & $\begin{array}{c}\text { Sprouted buds } \\
\text { after 180 days S }\end{array}$ & $\begin{array}{c}\text { Percent sprout- } \\
\text { ing }\end{array}$ \\
\hline & Sarole* & 1628 & 1495 & 91.8 & 195 & $11.0 \%$ \\
\hline & Nivegaon & 172 & 150 & 87.2 & 60 & $34.8 \%$ \\
\hline & Pratapgad & 285 & 222 & 0.77 & 35 & $12.28 \%$ \\
\hline & Kumbhalvane & 350 & 289 & 82.5 & 38 & $10.8 \%$ \\
\hline 7. & Koste* & 1090 & 996 & 91.3 & 310 & $28.4 \%$ \\
\hline 8. & Amruta- Dapoli* & 1351 & 1219 & 90.2 & 334 & $24.7 \%$ \\
\hline 9. & Amruta-Shirgaon & 535 & 496 & 93.2 & 179 & $33.4 \%$ \\
\hline Totis- Ratnagiri* & 49 & 37 & 75.5 & 30 & $61.22 \%$ \\
\hline & & 5048 & 498 & 84.69 & 311 & $52.8 \%$ \\
\hline
\end{tabular}

Table 2: No. of buds inoculated from each collection site with their Percent sterility and percent sprouting. Cultures from the locations which have been maintained in the laboratory beyond $\mathrm{S}_{4}$ stage in healthy stages are highlighted

The donor material collected from 9 different sites, material from only five locations- namely, Sarole, Koste, Panose, along with Amruta and Hatis varieties have shown high survival and sprouting ability. The grafted varieties of Amruta and Hatis have shown a high resistance to contamination along with maximum number of sprouting. The remaining cultures from Nivegaon, Pratapgad and Kumbhalavane continued to show contamination at every stage. Moreover, these shoot buds were more prone to drying than contamination in the inoculation media, thus, reducing their sprouting percentage. The percent sprouting has been calculated 
by dividing the sum of sprouted buds by the sum of collected buds and multiplied by 100 , thus giving the percent of 24.66 . Figure $4 . a$ shows exogenous contamination due to fungus and by phenolic leeching on the media surface in sprouted shoots. Figure 4.b shows endogenous contamination on the sprouted bud at the surface of the leaf at $\mathrm{I}_{2}$ stage. The remaining $24.66 \%$ of the sterile buds enter the multiplication stages from where they are further multiplied and grown, thus, increasing the viable shoots with each subculture.

\section{Post-Sterilization Treatment and Initiation of Multiplication} Stages

G. indica is a long day short night plant thus was incubated at $16 / 24 \mathrm{hr}$ photoperiod with the light intensity of 1500 lux at $27^{\circ} \mathrm{C}$ $[8,10]$. The inoculated test tubes were tied in bundles of seven to ensure uniform distribution of light to all the inoculums. Figure 4.c shows the inoculated test tubes tied in bundles of seven. The first contaminants begin to occur within 48-60hours; these are endogenous contaminants and hence selecting healthy donor plants is critical for establishing contaminant free cultures. Another major challenge faced during the study was the contamination due to fallen petioles on the medium during inoculation. The microbes identified responsible for the contamination are mainly of the genus Bacillus spp, Lactobacillus spp, Streptococcus spp, Flavabacterium spp, Pseudomonas spp, Kleibsiella spp, among the many others $[13,17,20,21]$. Polyphenols, the precursor of phenols are responsible for browning due to oxidation. These polyphenols are clustered in plastids around the meristematic cells and while cutting the shoot buds for explants, these may suffer an injury leading to the bursting of the plastids, thus exposing these polyphenols. They then release oxygen radicals, leading to the browning of the media $[3,18]$. Browning, however may not always be a sign of distress of the explants but it may subsequently lead to fungal contamination due to the rich phenols present in the medium, eventually rendering the explants useless [3]. If left unattended, these petioles would lead to heavy contamination, damaging the inoculated shoots. Thus, the petioles were meticulously removed and the inoculated buds were regularly transferred to newer $\mathrm{WM}_{\mathrm{I}}$ media after 15-20 days for two to three transfers from $\mathrm{I}_{0}$ stage to $\mathrm{I}_{3}$ stage. This step ensured surplus nutrition supply to the growing shoot bud.


Figure 4.a: Inoculated Buds with microbial contamination and browing.

Figure 4.b: Endogenous Contamination on asprouted bud at I3 stage which was sterile up to I2 stage.

Figure 4.c: Healthy sprouted buds of I2-I3 stage tied in bundles of seven. 


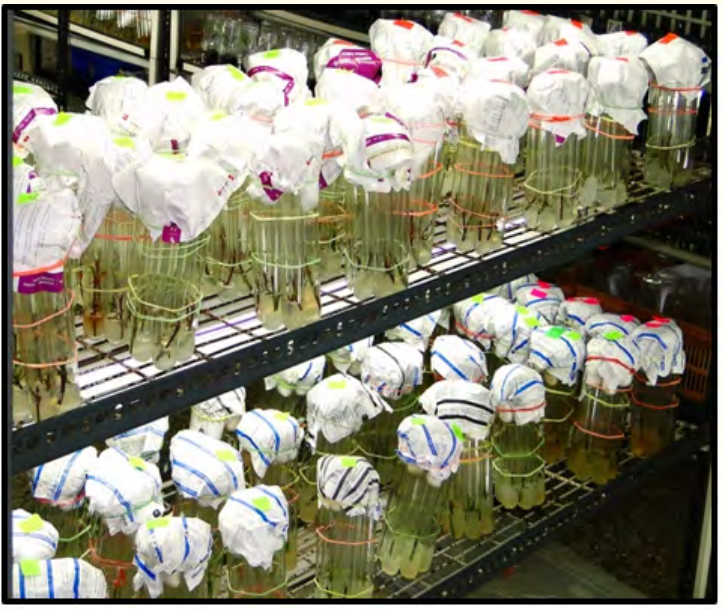

Figure 4.d: Inoculated buds tied in bundles of seven, incubated in culture room.

There have been reports which emphasize on the use of young trees of 9 to 12 years to overcome the obstacle of recalcitrance from cloning of elite, aged but healthy trees [9,22]. However, in the present study we have demonstrated that even cultures as old as above 60-70 years can be successfully cultured and multiplied in the laboratory upto $S_{4}$ stage if an optimum protocol is followed meticulously. Use of shakers has been made to eliminate phenolic leeching in Mangifera indica which hinders the growth of micropropagated cultures. The study reports only $24 \%$ of the cultures survive contamination [15]. Other reports have also made use of anti-oxidants such as Ascorbic acid or citric acid into the media or pre-soaking of the explants in the solution to combat the free radicals produced by the phenols $[3,11,23]$. Our present study eliminates phenolic browning in an extremely cost effective way without using shakers, thus increasing the sterile culture number to $87 \%$, with $24 \%$ viable sprouts.

$\mathrm{S}_{0}$ phase follows the $\mathrm{I}_{3}$ phase where the sprouted shoots are inoculated in the multiplication media with adequate growth hormones and incubated for 30-60 days before being transferred to a fresh medium in $250 \mathrm{~mL}$ conical flasks and are regularly subcultured after 50-60 days. Figure 5 shows the shifted buds in jam bottles with initiation media. After the subculturing, the shoots are subjected to in vitro and ex vitro rooting trials, the details of which have been published the 2019 article [10]. The plants are being acclimatized and hardened in an economical polyhouse set up with environmental conditions set to suit the growth of $G$. indica, details of which will be discussed in the upcoming article.

Figure 5 shows the step-wise growth of sterile shoots. Figure 5.a. to Figure 5.d shows the initiation of sprouting inWM $\mathrm{M}_{1}$ media and Figure 5.e shows the growth of the shoot in $\mathrm{WM}_{2}$ media in the $250 \mathrm{~mL}$ culture flasks.

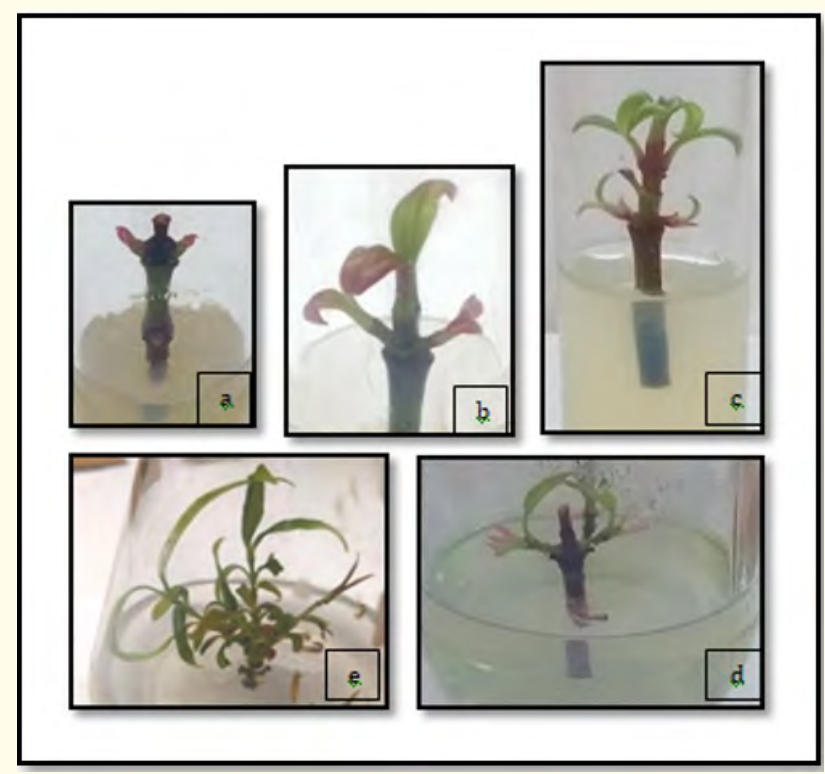

Figure 5.a: I0 stage- initiation of sprouting seen. Figure 5.b. I1 stage after 18-25 days.

Figure 5.c: I3 Stage, fully sprouted culture ready to be shifted in the Jam bottle with WMI media.

Figure 5.d: S0 stage of plant in Jam bottle of $105 \mathrm{~cm} \mathrm{X} \mathrm{55cm.}$

Figure 5.e: $\mathrm{S} 1$-S4 stage in $250 \mathrm{~mL}$ culture flasks.

We have clearly demonstrated that $G$. indica has shown its recalcitrance when mature shoot buds were used for meristem cultures under in vitro conditions. Out of $87 \%$ to $90 \%$ sterile buds, maximum 24\% shoot buds sprouted from meristems of explants of trees more than 60-70 years of age and other plantation trees which were 20-30 years old. In terms of success, $24 \%$ is quite a high number considering the recalcitrance in in-vitro response. Such type of data collection was only possible, as for the last three years the plant material is being meticulously collected and 
processed to develop a suitable protocol and achieve maximum sprouted buds. The shoots collected from each location have been maintained upto $\mathrm{S}_{4}$ stages in the culture room of the laboratory at the time of submission of this manuscript. Our next article deals with the aspect of ex vitro rooting and grafting of these in vitro grown shoots as 'scions' and polyhouse grown seedlings as 'root stocks'. The hardening and acclimatization using an economical polyhouse is the highlight of the work, for which the manuscript is under preparation. In India, rainy season is the time when field trials are initiated in forests and for plantations throughout. We are hopeful the plants developed through this technology will go for such field trials in June. CSIR-NCL has previously developed many such in vitro technologies for trees like Teak, Eucalyptus and Bamboos since 1985 for societal benefits.

\section{Conclusion}

Garcinia indica is medicinally rich, economically valuable tree species of the Western Ghats. The present study focuses on solving two major challenges faced during the initiation of in vitro cultivation of $G$. indica, which are microbial contamination and phenolic exudation of the shoot buds. With collection of the donor plant from the rightful locations and meticulous approach to the sterilization treatments, maximum number of healthy, sprouted shoots of $G$. indica can be obtained, which can then be clonally propagated to benefit pharmaceutical and the cottage industries.

\section{Bibliography}

1. Michael W Bairu., et al. "Physiological and developmental problems encountered by in vitro cultured plants". Plant Growth Regulation 63.2 (2011): 101-103.

2. Romano A., et al. "Micropropagation Of Mature Cork-Oak (Quercus SuberL.):Establishment Problems". Scientia Genmdensis 18 (1992): 17-27.

3. George EF. "Plant Propagation by Tissue Culture, Parts 1 and 2". Edington, Wilts, Exegetics Ltd., (1996): 131-134.

4. Preece JE., et al. "Problems with Explant Exudation in Micropropagation". Department of Plant and Soil Science, Southern Illinois University, Carbondale, IL, (1991): 62901-4415, USA
6. Parasharami V., et al. "Recent Pharmacological advances of endangered species of southern India: Garcinia indica Choisy". Journal of Scientific Research and Reports 8.5 (2015): 1-10.

7. Rajasekharan PE., et al. "Conservation of medicinal plant biodiversity-an Indian perspective". Journal of Medicinal and Aromatic Plants 24 (2002): 132-147.

8. Deodhar S., et al. "Clonal propagation of female plants of GarciniaindicaChoiss: a tree species of high medicinal value". Journal of Applied Biology and Biotechnology 2.06 (2014): 1825.

9. Pious Thomas and MB Ravindra. "Shoot tip culture in mango: Influence of medium, genotype, explant factors, season and decontamination treatments on phenolic exudation, explant survival and axenic culture establishment". Journal of Horticultural Science 72.5 (1997): 713-722.

10. Gauri M., et al. "Optimization of IBA for efficient survival of micro propagated Garcinia Indica Choisy shoots using in vitro and ex vitro rooting techniques". Asian Plant Research Journal 2.4 (2019): 1-9.

11. Ishtiaq Ahmad., et al. "Lethal Effects of Secondary Metabolites on Plant Tissue Culture". American-Eurasian Journal of Agricultural and Environmental Sciences13.4 (2013): 539-547.

12. Ibrahim Ilker Ozyigit. "Phenolic changes during in vitro organogenesis of cotton (GossypiumhirsutumL.) shoot tips". African Journal of Biotechnology Vol. 7.8 (2008): 1145-1150.

13. Barbara M Reed and P Tanprasert. "Detection and control of bacterial contaminants of plant tissue cultures A review of recent literature". Plant Tissue Culture and Biotechnology 3.1 (1995): 137-142.

14. Xiaomi Young. "Effects of a non-ionic surfactant on Plant Growth and Physiology". A Dissertation. (2008).

15. SS Raghuvanshi., et al. "Plant regeneration of Mangifera indica using liquid shaker culture to reduce phenolic exudation". Plant Cell Tissue and Organ Culture 41.1 (1995): 83-85.

5. Kokum farming for beginners, Agri Farming website (2019). 
16. Brian WW Grout. "Meristem-Tip Culture for Propagation and Virus Elimination Methods m Molecular Biology". Plant Cell Culture Protocols 7.11 (1995).

17. C Leifert., et al. "Contaminants of plant-tissue and cell cultures" A review World Journal of Microbiology and Biotechnology 7.4 (1991): 452-469.

18. Erica EB. "Special symposium: In vitro plant recalcitrance- Do free radicals have a role in plant tissue culture recalcitrance?". In Vitro Cellular and Developmental Biology 36.3 (2000): 163170.

19. Parasharami Varsha A., et al. "Bud Break and Plantlet Regeneration in Vitro from Mature Trees of PinusroxburghiiSarg". Current Science 84.2 (2003): 203-208.

20. C Leifert., et al. "Bacterial Contaminants of Micropropagated Plant Cultures". Journal of Applied Bacteriology (1989): 353361.

21. Ummey Habiba., et al. "Endogenous Bacterial Contamination During In vitro Culture of Table Banana: Identification and Prevention". Plant tissue culture 12.2 (2002): 117-124.

22. Brent H Mccown. "Special Symposium: In Vitro Plant Recalcitrance RecalcitranceOf Woody And Herbaceous Perennial Plants: Dealing With Genetic Predeterminism In Vitro". In Vitro Cellular and Developmental Biology - Plant 36.3 (2000):149-154.

23. Rabha Abdelwahd., et al. "Use of an adsorbent and antioxidants to reduce the effects of leached phenolics in in vitro plantlet regeneration of faba bean". African Journal of Biotechnology 7.8 (2008): 997-1002.

\section{Volume 3 Issue 7 July 2019}

C All rights are reserved by Shubha $S$ Manvi and Varsha A Parasharami. 